\title{
JOSÉ YVAN PEREIRA LEITE, O ENGENHEIRO-EDUCADOR QUE PLANTAVA SONHOS E COLHIA ESPERANÇA
}

\author{
O. M. MEDEIROS NETA*, M. J. V. F. LEITE \\ Universidade Federal do Rio Grande de Norte \\ olivianeta@gmail.com*
}

Submetido 3/12/2019 - Aceito 3/12/2019

DOI: $10.15628 /$ holos. 2019.9228

\section{RESUMO}

Este texto sobre o engenheiro-educador José Yvan assenta-se na interface entre a história e a biografia. Formado em Engenharia de Minas pela Universidade Federal da Paraíba, no ano de 1987; no ano de 1993, ingressou no Instituto Federal de Educação, Ciência e Tecnologia do Rio Grande do Norte Este engenheiro atuou por 26 anos como professor e pesquisador na área de tecnologia mineral, exercendo também funções como pró-reitor de pesquisa e editor de revista científica. José Yvan faleceu em 10 de junho de 2019.
Pela perspectiva da biografia histórica na acepção de Le Goff e objetivou-se estudar sobre como José Yvan Pereira Leite constitui-se como engenheiro-educador. $\mathrm{O}$ engenheiro-educador é um e outro, ao mesmo tempo é substantivo, é próprio, é epistêmico. A partir de tais considera-se que, como engenheiro-educador José Yvan foi múltiplo, intenso, engenho, claro! Foi um homem de razão e sensibilidade, um semeador de sonhos e coletor de esperanças. José Yvan, vive!

PALAVRAS-CHAVE: Engenheiro-educador, Biografia, José Yvan Pereira Leite.

\section{JOSE YVAN PEREIRA LEITE, THE ENGINEER-EDUCATOR PLANTING DREAMS AND HARVING HOPEABSTRACT}

This text about the engineer-educator José Yvan is based on the interface between history and biography. Graduated in Mining Engineering from the Federal University of Paraiba, in 1987; In 1993, he joined the Federal Institute of Education, Science and Technology of Rio Grande do Norte. This engineer worked for 26 years as a professor and researcher in the area of mineral technology, also working as dean of research and editor of scientific journal . José Yvan died on June
10,2019 . From the perspective of historical biography within the meaning of Le Goff and aimed to study how José Yvan Pereira Leite is constituted as an engineereducator. The engineer-educator is one and the other, at the same time is noun, is proper, is epistemic. From these it is considered that, as engineer-educator Jose Yvan was multiple, intense, ingenious, of course! He was a man of reason and sensitivity, a sower of dreams and a hope collector. José Yvan, live!

KEYWORDS: Engineer-educator, Biography, José Yvan Pereira Leite. 


\section{PENSANDO SOBRE INGENIUM}

Engenharia e seus termos derivados em português, como engenheiro, vem do latim ingeniem que significa gênio ou aquele que produz ou gera talento ou qualidade nata. Assim, aqueles que praticam a engenharia seriam engenhosos? Quais as engenhosidades dos engenheiros? Este texto, em especial, é sobre as engenhosidades do engenheiro José Yvan Pereira Leite, doravante José Yvan.

Nascido em Natal/RN, no ano de 1962, formado em Engenharia de Minas pela Universidade Federal da Paraíba, no ano de 1987. Como reconhecimento ao seu legado profissional, José Yvan tem recebido homenagens em sua memória.

No dia 2 de setembro de 2019, foi instituído como patrono do recém-criado Centro de Tecnologia Mineral do Rio Grande do Norte, na cidade de Currais Novos/RN. Tem recebido homenagens de comunidades científicas reunidas em eventos nacionais, tais como o XXVIII Encontro Nacional de Tratamento de Minérios e Metalurgia Extrativa (ENTMME) ocorrido em Belo Horizonte/MG entre os dias 4 e 8 de novembro de 2019 e o XVI Seminário Nacional de Arranjos Produtivos de Base Mineral, ocorrido no período de 18 a 20 de novembro, Santa Gertrudes/SP. Ainda foi, paraninfo in memoriam da turma concluinte do Curso Técnico de Mineração do IFRN, em solenidade de formatura realizada no final do semestre letivo 2019.1.

José Yvan iniciou sua experiência profissional na área de mineração no ano de 1988, atuando na Escola de Mineração Gilberto Mestrinho, da Empresa Paranapanema, em Manaus/AM. Em 1990, fez a opção por retornar ao Rio Grande do Norte e continuar seus estudos junto ao Mestrado em Engenharia Química da Universidade Federal do Rio Grande do Norte.

No ano de 1993, ingressou no Instituto Federal de Educação, Ciência e Tecnologia do Rio Grande do Norte Este engenheiro atuou por 26 anos como professor e pesquisador na área de tecnologia mineral, exercendo também funções como pró-reitor de pesquisa e editor de revista científica. José Yvan faleceu em 10 de junho de 2019.

Este texto sobre o engenheiro educador José Yvan assenta-se na interface entre a história e a biografia, uma vez que "[...] na biografia histórica deve se fazer, ao menos em um certo grau, relato, narração de uma vida, ela se articula em torno de certos acontecimentos individuais e coletivos - uma biografia não 'événementielle' não tem sentido" (Le Goff, 1989, p. 1).

O que é um engenheiro educador? Seria o profissional egresso do curso de engenharia que vincula o ofício da engenharia e suas especificidades como a mecânica, a eletricidade, a mineração ou a construção civil à docência?

Estudos como os de Fraga et al (2007), Dwek (2008) e Cruz (2019) apresentam caracterizações sobre os engenheiros educadores. Segundo Fraga et al (2007) aos engenheiros educadores são atribuídas a valorização do saber popular, mas também a desmistificação do saber acadêmico como verdade absoluta, além da produção de tecnologias adequadas aos empreendimentos econômicos solidários.

E, de acordo com esta assertiva, Dwek (2008) destaca que os Engenheiros Educadores são normalmente formados por meio da relação entre a prática de incubação e os estudos teóricos, ao atuarem em empreendimentos econômicos solidários (EES), embora outros tipos de formação para este papel sejam possíveis. 
Para Cruz (2019, p. 85), um engenheiro educador deve contemplar as seguintes habilidades: empatia, capacidade de dialogar, senso crítico e abertura para se seguir continuamente aprendendo.

A empatia e capacidade de dialogar exprime a "[...] forma clara e acessível, e de escutar o outro em profundidade. É isso que o/a tornará capaz de conhecer o sistema de saber-crença do grupo com o qual está trabalhando, além de conseguir estabelecer uma comunicação horizontal e verdadeiramente de duas mãos com ele" (Cruz, 2019, p. 85).

Já o senso crítico, para Cruz (2019, p. 85), volta-se à possibilidade de "enxergar no grupo com o qual trabalha, pessoas capazes tanto de reflexão, consciência e práxis - habilidades cujo desenvolvimento, a partir disso, ele/a estimulará continuamente nos membros do grupo quanto, exatamente por essas potencialidades, (possíveis) sujeitos ativos dos seus próprios processos de libertação."

E a abertura para aprender representaria para o engenheiro-educador a "[...] consciência de que aquilo que se sabe será sempre insuficiente para a transformação social almejada, podendo vir a ser continuamente alargada tanto a partir da reflexão sobre os resultados que a sua prática sobre o mundo (social) produz" (Cruz, 2019, p. 85).

Para tanto, ressalta-se que o engenheiro educador configura-se como uma formulação constituída por um substantivo seguido de um adjetivo, o qual qualifica o engenheiro e sua prática. No entanto, acredita-se que há uma integração entre as partes, as quais constituem uma unidade semântica com sentido próprio que exprime um lugar de fala e uma prática imbricada à história e às dimensões pessoais e profissionais.

O engenheiro-educador é um e outro, ao mesmo tempo é substantivo, é próprio, é epistêmico. A partir de tais considerações, é que objetiva-se estudar sobre como José Yvan Pereira Leite constitui-se como engenheiro-educador.

\section{ENGENHOSIDADES...}

O Em 14 de junho de 2019, saíram às ruas de diversas cidades do Brasil milhares de manifestantes em manifestação contra a reforma da previdência social proposta pelo presidente do Brasil, Jair Bolsonaro eleito pelo partido Social Liberal para mandato que teve início em janeiro de 2019. Neste dia, um dos manifestantes levava um cartaz com o seguinte poema:

Caminho sempre em frente

Caminhar é verbo

Luto é substantivo

Nesse caminho, encontro na natureza arte

Se a ciência encanta o futuro

Luto também é verbo

José Yvan Leite é terno.

(Rafael Leite Freire) 
O poema enlaça as palavras caminhar e luto como verbo e a menção a "José Yvan Leite é terno". Rafael Leite Freire é um jovem professor de Geografia e sobrinho de José Yvan e, quatro dias após a morte do tio, homenageia-o em uma manifestação a favor dos direitos do povo brasileiro.

Em 30 de maio de 2019, dias antes, quem estava na manifestação era José Yvan, protestando contra cortes na educação pública. Percorreu as ruas da cidade do Natal ao lado de diversos outros manifestantes e ao chegar em casa, após a caminhada, sentiu-se mal, vindo a falecer em 10 de junho de 2019 por complicações decorrentes de infarto sofrido no dia da referida manifestação.

O engenheiro-educador saiu às ruas para protestar a favor da educação pública e manutenção dos direitos dos cidadãos brasileiros. Era ele professor e pesquisador vinculado ao então Instituto Federal de Educação, Ciência e Tecnologia do Rio Grande do Norte. Em 1993, ingressou nesta instituição como professor da área de tecnologia mineral para atuar no Curso Técnico de Mineração, haja vista sua formação na graduação de Engenharia de Minas pela Universidade Federal da Paraíba (1982-1987).

Anos antes da atuação como professor, recém-formado, José Yvan atuou como engenheiro de minas de 1988 a 1990 na Escola de Mineração da Fundação Gilberto Mestrinho/Empresa Paranapanema ocupando funções como formador de Técnicos em Mineração e de Chefe do Laboratório de Tratamento de Minérios. (Leite, 2019a). Assim, os registros realizados por José Yvan em seu Currículo Lattes indiciam a articulação à prática profissional entre a docência e a tecnologia mineral.

No texto de apresentação do perfil do Currículo Lattes, José Yvan registrou que

\begin{abstract}
Possui graduação em Engenharia de Minas pela Universidade Federal da Paraíba (1987) e mestrado em Engenharia Química pela Universidade Federal do Rio Grande do Norte (1992). Atualmente é professor do Instituto Federal de Educação, Ciência e Tecnologia do Rio Grande do Norte. Tem experiência na área de Engenharia de Minas, com ênfase em Métodos de Concentração e Enriquecimento de Minérios, atuando principalmente nos seguintes temas: caracterização tecnológica, separação mineral, meio ambiente com ênfase em processamento mineral. (Leite, 2019a).
\end{abstract}

Como professor e pesquisador na área de Engenharia de Minas, José Yvan pode se constituir como um engenheiro-educador substantivo ou seja cuja composição articulava e integrava a formação e as práticas, com a função de denominar um ofício pautado pela techné que delineia a arte e destreza relativos também à engenharia.

A prática de engenheiro-educador, então, vincula-se à afirmação de Aristóteles de que "a técnica é um hábito criador acompanhado de razão verdadeira, cujo princípio se encontra no criador e não no criado" (apud Simões, 2010, p. 287).

Foi desta forma que as aulas e as pesquisas junto ao Laboratório de Tecnologia Mineral do IFRN se constituíram enquanto espaços-tempos criativos e vinculados a acontecimentos individuais e coletivos, centrados nas relações sociais com vistas à (re)criações engenhosas.

Assim, fora com a produção de um equipamento para separação mineral premiado na $V$ Mostra Tecnológica do IFRN no âmbito da Semana de Ciência, Tecnologia e Extensão do IFRN (SECITEX), ocorrida de 28 a 30 de novembro de 2017, no Campus Caicó (IFRN, 2017). O 
equipamento foi desenvolvido no âmbito do projeto "Alternativas para extração de contaminantes do processamento de quartzo de alta pureza" desenvolvido entre os anos de 2016 e 2017.

Se ingeniem significa gênio ou aquele que produz ou gera talento ou qualidade nata, esta insígnia caracterizava José Yvan como comprometido e integrado com um próprio desta composição semântica: engenheiro-educador.

O entendimento de engenheiro-educador o próprio assevera a indissociabilidade da vida pessoal e profissional, fazendo com as duas uma simbiose com vistas à formação integral, pautada pelas dimensões da ciência, da cultura, da tecnologia e do trabalho ${ }^{1}$.

A ciência, a cultura, a tecnologia e o trabalho foram marcas às pesquisas e ensino de José Yvan e estes elementos não se limitavam aos limites físicos do IFRN, pois animavam também as redes sociais, por entender que a formação se dava pelos aspectos da transformação social, sendo o conhecimento e sua produção, uma das possibilidades. Talvez por isto, na linha do tempo do Facebook, por exemplo, dedicava-se a mediar e comunicar sobre física, música, medicina, artes visuais, filosofia e democracia (Leite, 2019b).

$E$, no Twitter atentava às discussões sobre a equidade de gênero na ciência e novos horizontes para pesquisa e inovação, por exemplo. Este tema foi basilar às problematizações referentes às pesquisas que desenvolvia no âmbito do projeto "Inserção de mulheres cientistas na área de Processamento Mineral" ${ }^{2}$.

Sobre o engenheiro-educador constituindo-se como um próprio, uno e integrado, ressalta-se o nome do perfil "Pesquisa \& Inovação" e a proposta da página como sendo de "Divulgação do Prof. José Yvan Leite".

Figura 1: Perfil da conta de Twitter de José Yvan Pereira Leite

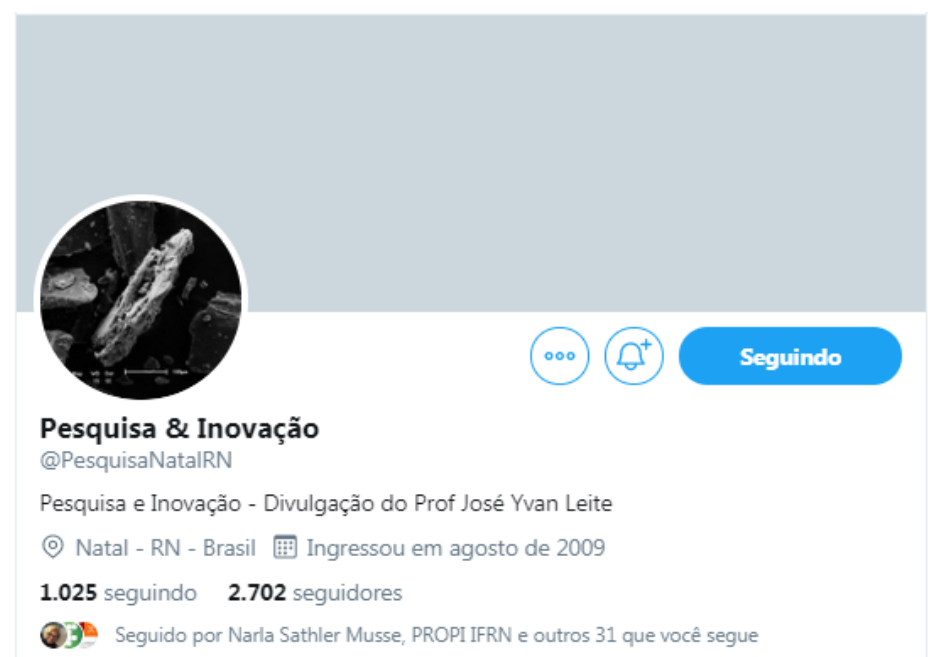

Fonte: Leite, J. Y. P. (2019c). Pesquisa \& Inovação. Natal, 2019. Twitter: @PesquisaNatalRN. Disponível em: https://www.google.com/url?q=https://twitter.com/PesquisaNatalRN . Acesso em: 15 nov. 2019.

\footnotetext{
1 Para maiores informações acerca da discussão sobre formação humana ver Ciavatta (2005). Para discussões referentes à formação humana na Educação Profissional ver Moura (2007).

2 Para acessar o perfil público da conta do Twitter acessar @PesquisaNatalRN. Disponível em: https://www.google.com/url?q=https://twitter.com/PesquisaNatalRN
} 
No que se refere ao engenheiro-educador epistêmico, os sonhos, a vida engajada e a prática se articularam em escritos como os editoriais da Revista Holos ${ }^{3}$. José Yvan, atento à técnica e à tecnologia, ao contexto político e social, atuou como editor da Holos de 2009 a 2019.

Como editor, ampliou o número de publicações no periódico, indexou a revista em indexadores de diversas partes do mundo o que ampliou o índice de citações dos artigos publicados ${ }^{4}$, o que deu visibilidade a revista e por extensão ao IFRN. Mas, o engenheiro-educador epistêmico tem na Holos e no sentido do termo uma metáfora, pois se constituía como um todo.

Na Holos, a defesa de uma ciência aberta, a preocupação com a comunicação científica para a transformação social a partir de seu papel formador, a análise da conjuntura política e temas referentes à equidade de raça, gênero e classe social figuravam nos artigos publicados, mas também nos editoriais. Na Holos, José Yvan se completava e se permitia escrever, na forma de caracteres, seu "caos criativo", sua visão de mundo, seus sonhos e práticas para horizontes holísticos.

No último editorial que escreveu para a Holos, José Yvan apresenta uma análise da revista Holos a partir de acessos ao portal, número de usuários cadastrados e, ao mesmo tempo, estabelece comparações com os anos anteriores, apresentando um horizonte de expectativas para o futuro do periódico, em 2019. (Leite, 2018).

Neste último editorial, José Yvan escreve que:

O tempo é de reafirmar caminhos da ciência e tecnologia, que compartilha conhecimentos, exalta a paz e a solidariedade entre os povos.

O momento é para agradecer autores e leitores, que com suas publicações e leituras valoram o periódico, bem como o trabalho dos avaliadores ad hoc e o conselho editorial pela manutenção da qualidade do que é publicado (Leite, 2018, p. 1, grifo nosso).

O tempo de reafirmar os caminhos da ciência e da tecnologia e de agradecer indiciam o ato reflexivo e analítico de José Yvan, bom como uma perspectiva engajada com tempos-espaços cada vez mais marcados pela força da solidariedade social e da ciência e seu poder (trans)formador.

\section{3 (IN)CONCLUSÕES SOBRE INGENIUM}

Este texto teve como eixo reflexões sobre as engenhosidades do engenheiro José Yvan Pereira Leite. Apresentou-se fragmentos de vida, histórias e práticas de um engenheiro-educador que e ao mesmo tempo é substantivo, próprio e epistêmico.

Como engenheiro-educador foi múltiplo, intenso, engenho, claro! Foi um homem de razão e sensibilidade, um semeador de sonhos e coletor de esperanças. José Yvan, vive! Está

\footnotetext{
${ }^{3}$ A versão eletrônica da revista está disponível no link http://www2.ifrn.edu.br/ojs/index.php/HOLOS .

4 Para maiores informações ver https://scholar.google.com.br/citations?user=MXdJhkAAAAAJ\&hl=ptBR\&authuser=1.
} 
presente em cada um de nós que o conheceu, que leu seus artigos e editoriais, que ouviu conversas de seus alunos, que recebeu suas cartas e e-mails sobre a tecnologia mineral.

José Yvan, presente!

\author{
José Yvan: \\ Jovial \\ Otimista \\ Sábio e sensível \\ Eclético... \\ Yes... ele é \\ Valoroso \\ Adorável e \\ Nerd... adora um caos criativo \\ (Olivia Morais de Medeiros Neta)
}

\title{
REFERÊNCIAS
}

Ciavatta, M. (2005). A formação integrada: a escola e o trabalho como lugares de memória e de identidade. Trabalho necessário. Niterói, (3)2005. 1-20. Disponível em: http://www.uff.br/trabalhonecessario/images/TN 03/TN3 CIAVATTA.pdf Acesso em: 14 ago. 2019.

Cruz, C. C. (2019). Engenheiro educador: experiências brasileiras de formação do perfil técnico capaz de praticar engenharia popular. CTS: Revista iberoamericana de ciencia, tecnología y sociedad, 14(40), 81-110.

Dwek, Maurício. (2008). Perspectivas para a formação em engenharia: o papel formador e integrador do engenheiro e o engenheiro educador. 2008. Tese de Doutorado. EPUSP.

IFRN - Instituto Federal de Educação Ciência e Tecnologia do Rio Grande do Norte. (2017). Projetos do Campus Natal-Central conquistam prêmios na SECITEX 2017, c2017. Notícias. Disponível em: http://portal.ifrn.edu.br/campus/natalcentral/noticias/projetos-do-campusnatal-central-conquistam-premios-na-secitex-2017. Acesso em: 10 nov. de 2019.

Le Goff, J. (1989). Comment écrire une biographie historique aujourd'hui?. Le débat, 54(03).

Leite, J. Y. P. (2018). Editorial. Holos, 8, 1-2. Disponível em: https://doi.org/10.15628/holos.2018.8147 Acesso em: 15 nov. 2019. 
Leite, J. Y. P. (José Yvan Leite). (2019a). Currículo Lattes. Natal, 2019. Disponível em: https://www.google.com/url?q=http://lattes.cnpq.br/4028840452449224\&sa=D\&ust=1573 910104033000\&usg=AFQjCNHK82Z9qTTKoyTZ6oLuaBvabLkMLw

. Acesso em: 10 nov. 2019.

Leite, J. Y. P. (José Yvan Leite). (2019b). Linha do tempo. Natal, jun. 2019. Facebook: joseyvan.leite. Disponível em: https://www.facebook.com/joseyvan.leite. Acesso em: 15 nov. 2019.

Leite, J. Y. P. (2019c). Pesquisa \& Inovação. Natal, 2019. Twitter: @PesquisaNatalRN. Disponível em: https://www.google.com/url?q=https://twitter.com/PesquisaNatalRN . Acesso em: 15 nov. 2019.

Moura, D. H. (2007). Educação básica e educação profissional e tecnológica: dualidade histórica e perspectiva de integração. Holos, Natal, (2), 1-27. Disponível em: <http://www2.ifrn.edu.br/ojs/index.php/HOLOS/article/viewFile/11/110> Acesso em: 04 ago. 2019.

Schmidt, B. B. (2014). Biografia: um gênero de fronteira entre a história e a literatura. Narrar 0 passado, repensar a história. Campinas, SP: Unicamp, 191-202.

Simões, C. A. (2010). Educação técnica e escolarização de jovens trabalhadores. In: Moll, Jaqueline (Org.). Educação profissional e tecnológica no Brasil contemporâneo: Desafios, tensões e possibilidades. Porto Alegre: Artmed, p. 96-117. 